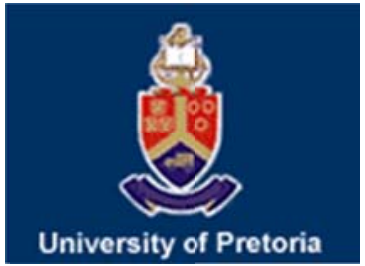

University of Pretoria Department of Economics Working Paper Series

The Relationship between Monetary Policy and Uncertainty in Advanced Economies: Evidence from Time- and Frequency-Domains

Semih Emre Çekin

Turkish-German University

Besma Hkiri

University of Jeddah

Aviral Kumar Tiwari

Montpellier Business School

Rangan Gupta

University of Pretoria

Working Paper: 2019-04

January 2019

Department of Economics

University of Pretoria

0002, Pretoria

South Africa

Tel: +27 124202413 


\title{
The Relationship between Monetary Policy and Uncertainty in Advanced Economies: Evidence from Time- and Frequency-Domains
}

\author{
Semih Emre Çekin* \\ Department of Economics, Turkish-German University, Email: scekin@tau.edu.tr \\ Besma Hkiri \\ College of Business, University of Jeddah, Saudi Arabia. Email: bHkiri@uj.edu.sa \\ Aviral Kumar Tiwari \\ Montpellier Business School, 2300, avenue des Moulins, 34185 Montpellier cedex 4 \\ 0002, France. Email: aviral.eco@gmail.com \\ Rangan Gupta \\ Department of Economics, University of Pretoria, Pretoria, 0002, South Africa. Email: \\ rangan.gupta@up.ac.za
}

\begin{abstract}
In this work we offer new insight into the relationship between interest rates and uncertainty for several advanced economies (Canada, EU, Japan, UK, US) for the period 2003-2018. For this purpose, we utilize the wavelets methodology, which allows us to analyze how the relationship changes over time and across different frequencies and to make inference about causality. To analyze a wide range of frequencies, and because our analysis contains the post-2008 period as well, we use the daily shadow interest rate measure of Krippner $(2012,2013)$ to capture the stance of monetary policy making at the zero lower bound. We also use the daily uncertainty measure by Scotti (2016), which measures uncertainty related to the real economy. Our findings suggest that there is significant comovement across time and across different frequencies in all the countries we analyze. Corresponding to the similar, yet different conduct of monetary policy, we also find that the relationship exhibits different characteristics and causality in all the economies we analyze, implying that one must be careful not to draw generalized conclusions.
\end{abstract}

Keywords: Interest Rate, Uncertainty, Advanced Economies, Wavelet

JEL Codes: C22, E52, E58

${ }^{*}$ Corresponding author. 


\section{Introduction}

The topic of uncertainty has been a subject of interest in the macroeconomic literature for several decades.In some of the earlier works, authors such as Dixit (1989) focused on the analysis of investment decisions of firms when faced with macroeconomic uncertainty, whereas others such as Baldwin and Krugman (1989) analyzed the effect of uncertainties surrounding exchange rate movements on trade flows. While many works followed these authors and explored the channels through which uncertainties affect the economy in the following years ${ }^{1}$, Bloom (2009) stands out. In this influential work, the author used firm-level data within a structural framework with timevarying volatility and an uncertainty measure based on stock market volatility to show that macroeconomic uncertainty can lower productivity growth. More recently, Bloom (2014) argued that uncertainty is countercyclical and that recessions increase uncertainty, which in turn can exacerbate the effects of the business cycle, implying - as in Bloom (2009) - an endogenous link between economic activity and uncertainty. In yet another contribution aimed at disentangling the causality and endogeneity of uncertainty and real economic activity, Ludvigson et al. (2015) argue within a structural VAR (SVAR) setup that financial uncertainty likely is a trigger of recessions and that uncertainty of real activity is an endogenous response of the cyclical movement.

As is apparent from these contributions, there is a growing number of works analyzing the link and causality between uncertainty and business cycles. A topic that has received similar attention is the relationship between uncertainty and the conduct of monetary policy. As discussed by Brainard (1967), the principle of attenuation suggests that central banks' response is dampened when they are faced with uncertainty associated with the effect of rate changes. In contrast, others such as Giannoni (2002) or Söderström (2002) have suggested that monetary authorities may react more aggressively under uncertainty. Following these discussions, several authors incorporated uncertainty measures into monetary policy reaction functions to analyze whether and to which extent uncertainty plays a role.Estimating a Taylor rule augmented with principal components and uncertainty, Ma et al. (2018) find that the Federal Reserve reacted to uncertainty by decreasing the policy rate. In a similar study, Christou et al. (2018) examine the reaction of the central banks of several advanced economies to uncertainty using a quantile regression approach. They find that central banks in advanced economies react more aggressively to uncertainty at lower quantiles, suggesting an aggressive monetary policy stance as the zero lower bound is approached.A contribution that attempts to capture uncertainties using news shocks is Gürkaynak

${ }^{1}$ See Dixit and Pindyck (1994) for a review of the literature. 
et al. (2005), who analyzed in their work how news shocks -captured as the difference of realized and expected values of macroeconomic variables - affect the term structure of interest rates. They conclude that contrary to the assumption of many standard models, long-term interest rates are affected by such news shocks. The analysis of the topic also has been of interest for the finance literature (see among others Hartzmark (2016), Leippold\&Matthys (2015) and Connolly et al. (2018). But in these contributions, modeling of uncertainty takes many forms and doesn't focus explicitly on the relationship between uncertainty as perceived by economic actors and the interest rate.

In this paper, we aim to contribute to this literature by analyzing the relationship between interest rates and uncertainty with wavelets using the uncertainty measure as constructed by Scotti (2016) and daily shadow interest rates as in Krippner (2013).We believe that with our approach we can address several important questions: is there comovement between the series, and if yes, what is the nature of the comovement? Does the comovement exhibit time variation and if yes, does it differ across different frequencies? Is there causality between the variables considered and if yes, does it vary over time?

The use of Wavelets is suited for this type of analysis as it allows for time-variation across different frequencies, and for the study of causality. We further believe that our uncertainty measure is appropriate for our analysis: while there are many different proxies for uncertainty such as the VIX index, disagreement in professional forecasts, stochastic volatility or the variance of innovations in GARCH models, the index of Scotti (2016) is particularly useful as it proxies for the uncertainty of real economic activity as perceived by economic actors in real time. This is in line with the growing recognition that perception of economic agents matters for general economic sentiment (see e.g. Alexopoulos \&Cohen (2015) or Donadelli (2015)).

In our analysis, we examine the relationship between economic uncertainty and interest rates for several developed countries, using daily data for US, EU, UK, Canada and Japan. Our results indicate that there is substantial time-variation across different frequencies for all countries that we examine. Specifically, we find that for the US, UK and Canada interest and uncertainty mostly move in opposite directions (i.e., are in anti-phase), whereas for the EU and Japan the two measures mostly comove positively (i.e., are in phase). Especially considering the increased understanding of the importance of uncertainty for the economy, we believe these results carry relevance for the growing literature of the effects of macroeconomic uncertainty. Our paper is organized as follows: section 2 details the methodology, section 3 presents the data used for the 
analysis, while section 4 discusses the results, with section 5 providing implications of the results obtained, and section 6 concluding the paper.

\section{Methodology}

The wavelet approach allows one to examine the behavior of time series jointly in frequency and time spaces. In our paper, we use wavelet coherence under the Morlet specification to assess the co-movements between uncertainty and interest rates within different contexts. Used by a growing number of researchers, the wavelet analysis has demonstrated its ability to explicitly expose and follow the time-scale varying outlines of time series. According to Aguiar-Conraria et al. (2008), the wavelet approach performs the estimation of the spectral characteristics of a time series as a function of time, revealing how the different periodic components of the time series change over time. More explicitly, this approach stretches to isolate slow and persistent movements. The wavelet approach allows us to describe the local behavior of heterogeneous markets participants. Indeed, some participants have an investment horizon of several minutes or hours to several days (e.g. when considering short-term movements of stock markets) while others may have an investment horizon of several weeks or months (e.g. with medium-term movements of the stock markets) or an investment horizon of several years (e.g. with long-term movements of the stock markets). In addition, the Wavelet approach is an appropriate tool to analyze the behavior of time series jointly in both the frequency and time spaces. Specifically, the wavelet coherence is employed under Morlet's specification. The wavelet is defined as $\psi_{u, s}(t)=$ $\frac{1}{\sqrt{s}} \psi\left(\frac{t-u}{s}\right)$. First, one should recall that a wavelet is a real-valued or a complex valued function $\psi($.$) defined over the real axis. Moreover, it is assumed that the wavelet is a square integrable$ function $\psi(.) \in L^{2}(\mathbb{R})$. In the above equation, $\frac{1}{\sqrt{s}}$ is the normalization factor, ensuring that the unit variance of the wavelet satisfies $\left\|\psi_{u, s}\right\|^{2}=1$ and $u$ denotes the location parameter, providing the exact position of the wavelet. $s$ is the scale dilatation parameter of the wavelet. It defines how the wavelet is stretched or dilated. In this regard, a higher scale implies a more stretched wavelet, which is appropriate for detection of lower frequencies. Formally, the Morlet's wavelet is given by $\psi^{M}(t)=\frac{1}{\pi^{1 / 4}} e^{i \omega_{0} t} e^{-t^{2} / 2}$ where $\psi^{M}(t)$ is the wavelet value at nondimensional time $t$ and $\omega_{0}$ is the central frequency of the wavelet which is equal to 6 .

\subsection{The continuous wavelet transform}


As in Rua and Nunes (2009) and Baruník et al. (2011), the continuous wavelet transform is given by $W_{x}(u, s)=\int_{-\infty}^{\infty} x(t) \frac{1}{\sqrt{s}} \overline{\psi\left(\frac{t-u}{s}\right)} d t$. Specifically, $W_{x}(u, s)$ is obtained by projecting the specific wavelet $\psi($.$) on the selected time series. The main advantage of the wavelet transform is$ the aptitude to decompose and then consequently reconstruct the function $x(t) \in L^{2}(\mathbb{R})$ :

$x(t)=\frac{1}{c_{\psi}} \int_{0}^{\infty}\left[\int_{-\infty}^{\infty} W_{x}(u, s) \psi_{u, s}(t) d u\right] \frac{d s}{s^{2}}, \quad s>0$

One should note that the main feature of the wavelet transform is the energy preservation of the selected time series. This property is employed for the power spectrum analysis which specifies the variance as follows: $\|x\|^{2}=\frac{1}{C_{\psi}} \int_{0}^{\infty}\left[\int_{-\infty}^{\infty}\left|W_{x}(u, s)^{2}\right| d u\right] \frac{d s}{s^{2}}$.

\subsubsection{Wavelet power spectrum}

Analogous to Torrence and Compo (1998) and Aguiar-Conraria et al. (2008), the wavelet power spectrum can simply be defined as $\left|W_{n}^{x}\right|^{2}$ and this measure assesses the local variance of each variable. The statistical significance, according to Grinsted et al. (2004), can be assessed relatively to the null hypothesis that the variable under consideration has a significant power spectrum, i.e., the signal is generated by an $A R(0)$ or $A R(1)$ stationary process with mean background power spectrum $\left(P_{f}\right)$. Based on Monte Carlo simulations through computing the white-noise and red-noise wavelet powers, Torrence and Compo (1998) show that, at each time $n$ and scale $s$, the corresponding distribution for the local wavelet power spectrum can be written as

$$
D\left(\frac{\left|W_{n}^{X}(s)\right|^{2}}{\sigma_{X}^{2}}<p\right) \Rightarrow \frac{1}{2} P_{f} \chi_{v}^{2}
$$

where $P_{k}$ is the mean of spectrum at the Fourier frequency $f$ that corresponds to the wavelet scale $s$ $(s \approx 1 / f)$, and $v$ takes the values of 1 or 2 for real or complex wavelets, respectively.

\subsubsection{Cross-wavelet power, wavelet coherence, and phase differences}

The cross-wavelet power shows the area in the time-scale space where the time series exhibit high common power. As noted by Aguiar-Conraria et al. (2008), the cross-wavelet power captures the local covariance of two time series in each frequency and shows the quantitative similarities of power between them. It is also interesting to note that low (high) scales are compressed wavelets allowing us to examine rapidly changing details related with high (low) frequencies, respectively. According to Hudgins et al. (1993), for each signal $X$ and $Y$, the individual wavelet spectra are specified as $W_{n}^{X}(s)$ and $W_{n}^{Y}(s)$, respectively. In the time-frequency 
analysis, the cross-wavelet between two signals is represented by the cross-wavelet spectrum $W_{n}^{X Y}(s)$ which is defined as in Eq. (3) ${ }^{2}$

$$
W_{n}^{X Y}(s)=W_{n}^{X}(s) W_{n}^{Y^{*}}(s)
$$

where $W_{n}^{Y^{*}}(s)$ is the complex conjugate of $W_{n}^{Y}(s)$ and * denotes complex conjugation. The cross-wavelet power is therefore given by $\left|W_{n}^{X Y}\right|$ and it measures the local covariance of two variables at each scale. Torrence and Compo (1998) show that the theoretical distribution of the cross-wavelet power of two signals with background power spectra $P_{k}^{X}$ and $P_{k}^{Y}$ acquires the following form:

$$
D\left(\frac{\left|W_{n}^{X}(s) W_{n}^{Y *}(s)\right|}{\sigma_{X} \sigma_{Y}}<p\right)=\frac{Z_{v}(p)}{v} \sqrt{P_{k}^{X} P_{k}^{Y}}(8)(4)
$$

Where $\sigma_{X}$ and $\sigma_{Y}$ designate the standard deviations of $x$ and $y$, respectively. $Z_{v}(p)$ is the confidence interval level related to the probability $p$ for a $p d f$ (probability density function), defined by the square root of the product of two $\chi^{2}$ distributions.

On the other hand, the wavelet coherency of two time series $x=\left\{x_{n}\right\}$ and $y=\left\{y_{n}\right\}$ is defined as the localized correlation coefficient between these series in the time-frequency space (Torrence and Compo, 1998). It is thus a very useful tool for detecting time series' comovements. Following Torrence and Webster (1999), the wavelet coherence is computed as the squared absolute value of the smoothed cross-wavelet spectra, normalized by the product of the smoothed individual wavelet power spectra of each time series:

$$
R^{2}(u, s)=\frac{\left|S\left(s^{-1} W_{x y}(u, s)\right)\right|^{2}}{S\left(s^{-1}\left|W_{x}(u, s)\right|^{2}\right) S\left(s^{-1}\left|W_{y}(u, s)\right|^{2}\right)}(5)
$$

Where $S$ denotes the smoothing parameter. In the no-smoothing case, the wavelet coherence will be equal to one. Additionally, the squared wavelet coherence coefficient satisfies this inequality $0 \leq R^{2}(u, s) \leq 1$. A value close to zero indicates weak correlation, while a value close to one signifies the presence of high correlation.

While the phase of a wave is defined as a fraction of a complete cycle which oscillates around a time-axis, the phase difference is a difference of the phase between two time series. In addition, the phase difference provides ideas about the lateness of the oscillations between two variables as a function of frequency. The phase difference of two time series, noted as $\phi_{x, y}$, characterizes the

${ }^{2}$ See Torrence and Compo (1998) for more details about cross-wavelet spectrum hypothesis and confidence levels. 
phase relationships between them. It effectively gives us information about the time series' positions in the pseudo-cycle. The phase difference is given as;

$$
\phi_{x, y}=\tan ^{-1}\left(\frac{\mathfrak{I}\left\{W_{n}^{x y}\right\}}{\mathcal{R}\left\{W_{n}^{x y}\right\}}\right) \text { with } \phi_{x, y} \in[-\pi, \pi] .
$$

For a more detailed understanding of this issue, we will consider two ideal cyclical time series $X$ and $Y$, where both are sine functions with different phases ${ }^{3}$. The interpretation of the phase as a lead or a lag has to be done relative to the phase difference. Based on Eq.6, we can identify the direction of causality between the two time series. Therefore, when the difference phase is given by $\phi_{1} \in[0, \pi / 2], X$ leads $Y$ by $\phi_{1}$ and when $\phi_{2} \in[\pi / 2, \pi], X$ lags $Y$ by $\phi_{2}$ (or $Y$ leads $X$ by $\phi_{2}$ ) by $\pi-\phi_{2}$. In addition, when the phase difference is $\phi_{3} \in[-\pi,-\pi / 2], X$ leads $Y$ by $\phi_{3}$, or in another words, $X$ leads $Y$ in anti-phase relationship by $\phi_{3}-\pi$ and when $\phi_{4} \in[-\pi / 2,0], Y$ leads $X$ in anti-phase relationship by $2 \pi-\phi_{4}$. However, the relationship between the two time series is unclear when the phase difference is equal to $\pi / 2$ or $-\pi / 2$. According to Ho et al. (2010), to better recognize the lead/lag relation between time series, when the phase difference is $\in[\pi / 2,-\pi / 2]$, it is important to transform each phase of each specified band wavelet into a sine function and make the pseudo cycle, making possible to judge the lead/lag relationship of the two time series at specified band.

In addition, the phase difference is comparable to causality in a Granger sense. In order to identify the direction of causality, which is given by the relative lag between the two time series, we use phase shift, which is interpreted as a lead or a lag between the time series. In this sense we can interpret the phase difference in terms of the arrow's direction. Arrows pointed to the right (left) indicate that variables are in phase (out of phase or anti-phase). If arrows move to the right and up (down), the first variable $X$ is leading (lagging). By contrast, if arrows move to the left and up (down), the variable $X$ is lagging (leading).

\section{Data}

As mentioned in the introduction, we use the daily index of Scotti (2016) to measure uncertainty. ${ }^{4}$ The index captures uncertainty related to the real economy as perceived by economic agents using Bloomberg expectations and realizations of several macro variables. To compile the

\footnotetext{
${ }^{3}$ We refer the reader to Ho et al. (2010) for definition of these technical issues.

${ }^{4}$ The data is available for fom: https://drive.google.com/file/d/1KkrQSXOxJMqb9eTEkQuGY7VlVsQomuU4/view.
} 
index, the author uses a dynamic factor model which is estimated to construct business conditions index and forecasting weights. Using these, uncertainty is then a weighted average of squared surprises from the macroeconomic variables. The data is constructed with daily frequency and is provided for the United States, Euro Area, United Kingdom, Canada and Japan for the period $15^{\text {th }}$ May, 2003-2 $2^{\text {nd }}$ October, 2017.

Figure 1 (Figures 1a and 1b)

Shadow interest rate and uncertainty index for the US
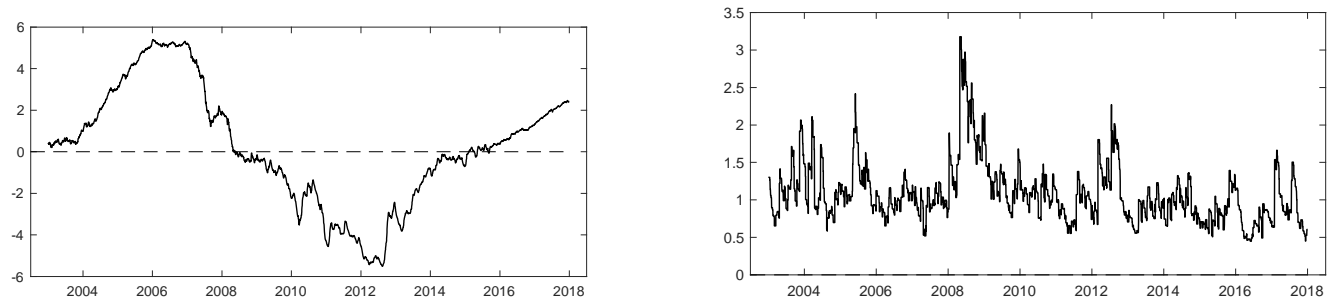

Figure 2 (Figures 2a and 2b)

Shadow interest rate and uncertainty index for the Euro Area
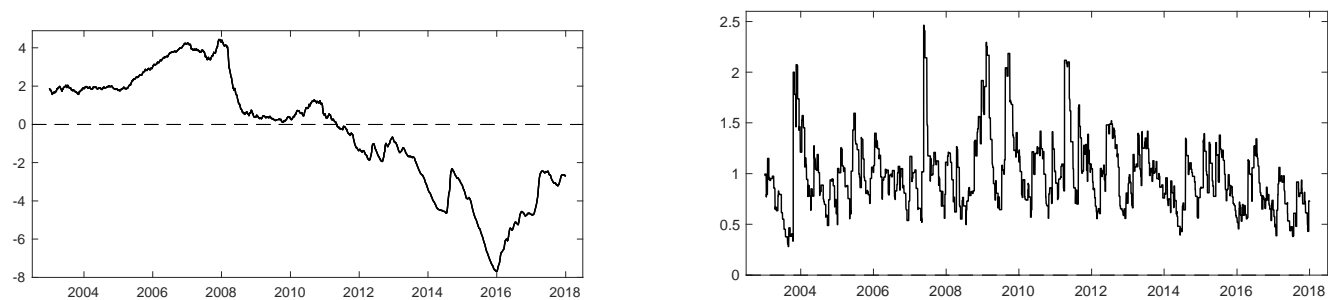

Figure 3 (Figures $3 a$ and $3 b$ )

Shadow interest rate and uncertainty index for the UK
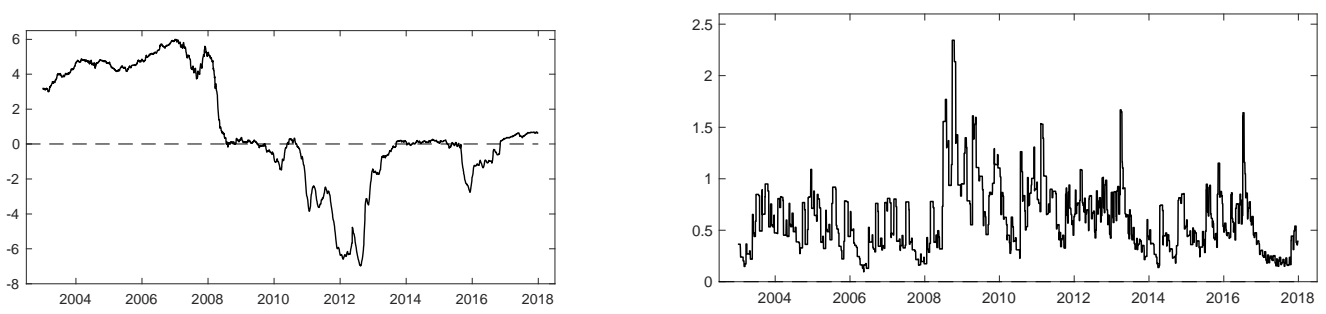
Figure 4 (Figures 4a and 4b)

Repo rate and uncertainty index for the Canada
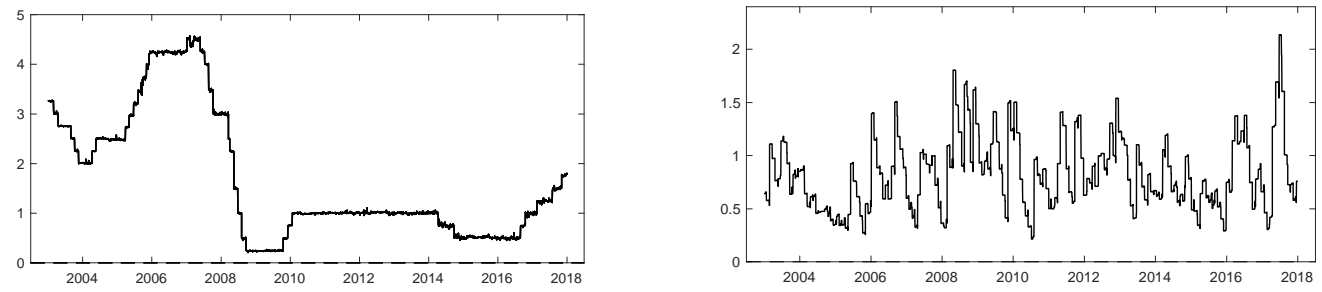

Figure 5 (Figures $5 \mathrm{a}$ and $5 \mathrm{~b}$ )

Shadow interest rate and uncertainty index for the Japan
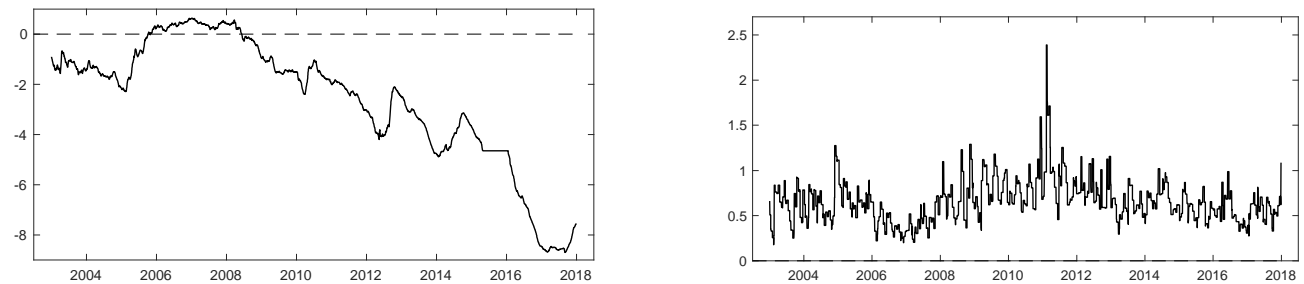

In addition to the uncertainty index, we use the daily shadow interest rate measure as introduced in Krippner $(2012,2013)$ for the US, Euro Area, UK and Japan. This option-based measure is a product of the estimation of a dynamic term-structure model that is an extension of a Gaussian affine term structure model which allows for negative rates. There are two reasons why we choose this measure: first, the countries we consider are all major developed countries and substantially decreased interest rates after the 2008 financial crisis. Because interest rates are constrained by the zero lower bound, we believe that shadow interest rates represents stance of monetary policy more appropriately, especially for those countries that implemented quantitative easing measures. ${ }^{5}$ Second, the interest rate measure is available at daily frequency and hence matches the daily uncertainty measure of Scotti (2016). For Canada we use the daily repo rate, obtained from the Bank of Canada, ${ }^{6}$ since it is the only country in our sample not to have pursued unconventional monetary policy (see Fontaine et al. (2017)). The use of daily data for interest

\footnotetext{
${ }^{5}$ The data can be downloaded from:https://www.rbnz.govt.nz/research-and-publications/researchprogramme/additional-research/measures-of-the-stance-of-united-states-monetary-policy/comparison-ofinternational-monetary-policy-measures.

${ }^{6}$ The data is available at: https://www.bankofcanada.ca/rates/interest-rates/.
} 
rates and uncertainty is specifically suited for our purpose since wavelets allow us to examine the dynamic relationship between interest rates and uncertainty for different frequencies over time. ${ }^{7}$

\section{Results}

\subsection{Wavelet coherency, phase difference analysis for US}

In this section we reveal our empirical findings. As pointed out above, to analyze the wavelet plots, we will base our interpretation on two factors; the arrow's direction and the plot's color bars. More precisely, as noted by (Vacha et al. 2013), the phase differences presented by black arrows allow us to distinguish between negative and positive correlations, indicating delay in the oscillation between two time series. When the arrows are directed to the right, the investigated time series are in phase and move together, i.e. are positively correlated. If, contrary, the examined time series are negatively correlated, they are anti-phase. Furthermore, alluding to Ben Salha et al. (2018), the intensity of correlation between two time series is revealed by colored areas. The plot's color bars demonstrate many colors ranging from blue to red. While blue color indicates that there is no correlation between the investigated time series (blue islands), the red color indicates high level of co-movement (correlation) between time series. On the other hand, the co-movement (the correlation) between studied time series vary in time and across frequency. Time and frequency are represented on the horizontal and the vertical axis, respectively. More precisely, the time series are decomposed to scales ranging from high (low scales) to low frequencies (high scales).In addition, the thick black contour encloses regions where the wavelet coherence is significant at the 5\% level against the red noise estimated from Monte Carlo simulations using phase randomized surrogate series. In our plots, the cone of influence (COI) is graphically represented by the lighter shade which delimits the important power regions.

The following plots correspond to wavelet coherence between uncertainty and interest rate and the phases' differences in different countries. Figure 6 (Fig.6a and Fig.6b) respectively reports the cross-wavelet power coherency between uncertainty index and interest rate over time and across frequencies and the phase differences for the US case.

\footnotetext{
${ }^{7}$ As a prelude to the wavelet analysis, Figures A1 to A5 in the Appendix of the paper present quantilesbased coherency (as developed by Baruník and Kley (2015))between uncertainty and interest rate across various quantiles. The figures in the left panel correspond to Real (Re) and the right panel for imaginary (Im) parts of the quantile coherency estimates for weeks (W), months (M) and years (Y), along with the 95 percent confidence intervals. Note, quantiles provide an indirect way of studying the time-varying nature of the relationship between the two variables, as they correspond to different states of uncertainty and interest rates. As can be seen, in general, the relationship between these two variables tend to be negative.
} 


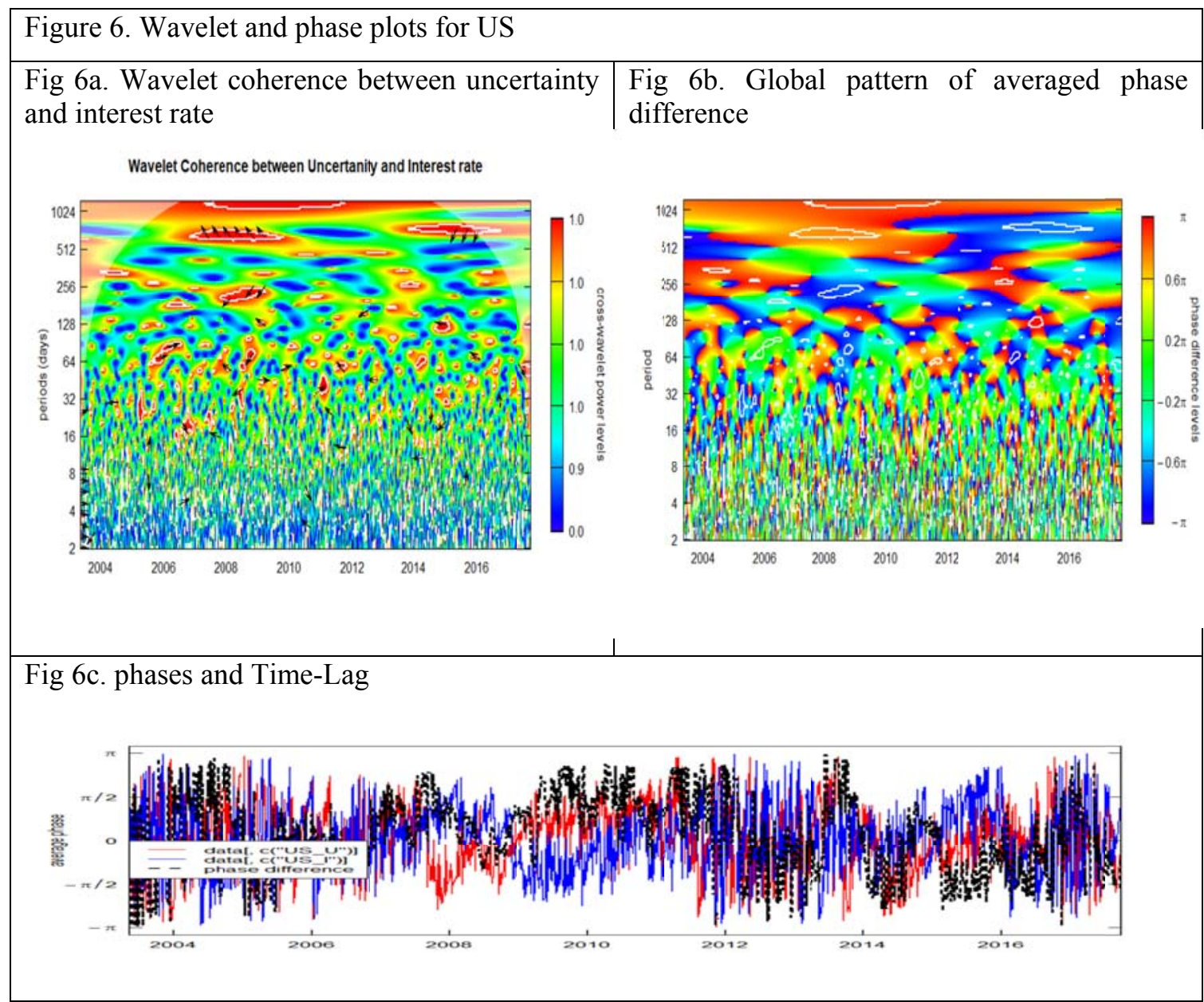

Note: a) wavelet coherency between uncertainty index and interest rate, b) Global pattern of averaged phase difference, c) The phases and Time-Lag. The white contour identifies the regions in which thespectrum is significant at the $5 \%$ level against red noise. The cone of influence (COI), indicated by the lighter shade which delimits the high power regions. Time and frequency (daily) are represented on the horizontal and vertical axes, respectively.

Fig.6a presents the wavelet coherence between uncertainty and interest rate from 2004 to 2016. Excluding the unsteady comovement between uncertainty index and interest rate at frequencies around2-128 days, we find a significant long-run comovement between the two time-series at low frequencies, especially between 256 and 1024 days. However, we are careful to interpret this comovement for two reasons. Firstly, this comovement was mostly localized at high scales (5121024 band of days) and secondly it is scattered over two sub-sample periods; from 2006 to the end of 2010 and from 2013 to the end of 2016. For the first sub-sample period (2006-2010), the uncertainty index and the US interest rate are anti-phase (move oppositely) as the arrows are 
pointed to the left and the uncertainty index is lagging. We note that this period corresponds to the US financial crisis where policy uncertainty was very high. For the second sub-period (20132016) and for the same frequency-band, the uncertainty index and the US interest rate move conversely as the arrows are pointed to the left and down indicating that they are anti-phase and the uncertainty index is leading.

In Fig.6b, we present the global pattern of averaged phase difference to check whether the two time-series (US uncertainty index and the interest rate) exhibit phase or anti-phase characteristics and especially whether they exhibit the lead-lag relationship. While this figure exhibits patterns that confirm our previous finding revealing that the two series comove within 64-256 and 512-1024 day cycles, the cyclical relationship (in phase/anti-phase) is not easily understood at average level. This is why we will rely on Fig.6cto analyze the pattern of average phase differences. Fig.6ccorresponds to the average phase difference (1-1012 day of frequency). Note that Phases and Phase-Difference (Phase.x- Phase.y)are also computed for different frequency bands ${ }^{8}$. For Fig (6c),the blue line represents the US interest rate index phase, the red line represents the US uncertainty index phase, and the blackdotted line represents the phase difference. It is interesting to note that, when the phase-difference is converted to an angle in the interval $[-\pi, \pi]$, an absolute value less (larger) than $\pi / 2$ indicates that the two series move in phase (anti-phase). In addition, the sign of the phase-difference indicates which series leads (lags) in the relationship. In this plot, we can analyze the relationship within three episodes: In the first two episodes, the interest rate index leads the US uncertainty index(on average) in anti-phase relationship $[-\pi,-\pi / 2]$ for the periods 2004-2006 and 2012-2016, implying a negative relationship between the two time-series. The third episode of the relationship corresponds to the period 2007-2011, where the phase plunges to the interval $[0, \pi / 2]$, indicating that the uncertainty index leads the interest rate index in anti-phase relationship. This result indicates that the uncertainty is negatively correlated with the interest rate in the US. This is not surprising as, during turmoil periods, uncertainty is high and considerably slows US bank credit growth (Bordo et al. 2016), or put alternatively interest rate is low, as observed particularly during the Great Recession.

\footnotetext{
${ }^{8}$ More precisely, we compute the phases for the 2-4 day, 4-8 day, 8-16 day, 16-32 day, 32-64 day, 64-128 day, 128-256 day, 256-512 day and 512-1024 day frequency bands. Plots are not reported to conserve space, but are available upon request addressed to the corresponding author.
} 


\subsection{Wavelet coherency, phase difference analysis for Euro Area}

Figure 7 (Fig. 7a to Fig. 7c) reports the wavelet coherency between uncertainty and the interest rate for the period 2004 to 2016 for the European case. Looking at high and medium scales, especially the 256-1024 day and 64-256 frequencies bands, the two time-series have a common and high coherency level, where the interest rate leads in the second quarter (2007-2011) and the European uncertainty index leads in the second half of the sample.

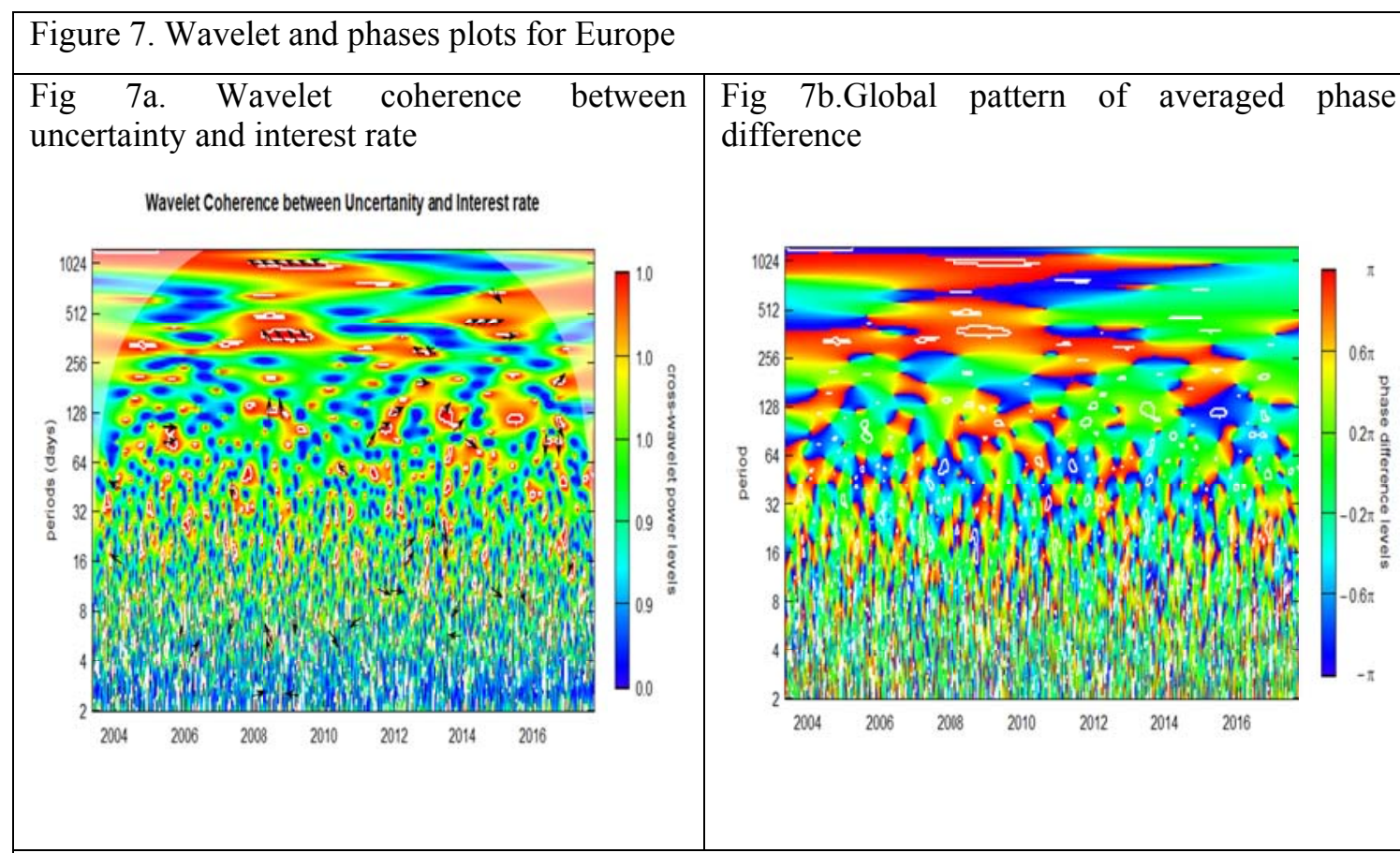

Fig 7c.Phases and Time-Lag

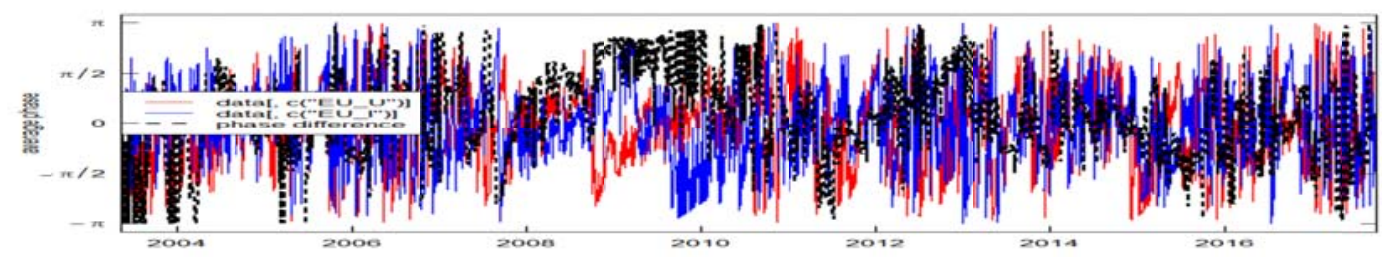

Note: a) Wavelet coherency between uncertainty index and interest rate, b) Global pattern of averaged phase difference, c) The phases and Time-Lag. The white contour identifies the regions in which the spectrum is significant at the $5 \%$ level against red noise. The cone of influence (COI), indicated by the lighter shade which delimits the high power regions. Time and frequency (daily) are represented on the horizontal and vertical axes, respectively.

The global phase difference is given in Fig. $7 \mathrm{~b}$ and reveals a strong relationship between the two series, especially localized in low frequencies and in general dispersed over all the sample period. However, it will be more interesting to understand the phase or anti-phase relationship from the average phase differences (Fig.7c). Looking to Fig.7c, it is understandable that for the period 
2009-2010the phase difference is localized between $[0, \pi / 2]$. This reveals that the European interest rate leads the uncertainty index in a phase movement. In addition, for the periods 20042008 and 2011-2016, the phase plunges mostly to the interval $[\pi / 2,-\pi / 2]$, indicative of aphase relation in which the uncertainty index leads the interest rate in general. Our findings indicate a positive relationship between uncertainty policy and interest rate.

\subsection{Wavelet coherency, phase difference analysis for United Kingdom}

Figure 8(Fig. 8a to Fig. 8c) reports plots of wavelet coherency and phase differences between economic uncertainty index and interest rate for the United Kingdom. Fig (8a) presents result of wavelet coherency between the uncertainty index for the UK and the interest rate and indicates a strong relationship between the two time-series, especially localized at high scales during the period 2006-2017, indicating the occurrence of extreme events at the middle and the end of the period. Noting that the vote to exit the European Union, known as Brexit, took place in 2016, it is why not surprising that this event lead to high economic and policy uncertainty in the UK. During this period, the arrows are directed to the left and up, revealing that the interest rate index is leading. While small islands of orange color are spread over the sample period, the lead-lag relationship is no longer clear. This result does not neglect the presence of some scenarios which inspire the relationship between the two time-series. We assume that the global power average phase difference(ranged between $[-\pi, \pi]$ given in (Fig $8 \mathrm{~b}$ ) and the outline of average phase differences(shown in (Fig 8c)) allow us to understand the accurate lead/lag relationship between the two time-series. Visual inspection for these plots reveals big areas of dark red color, mostly concentrated at low frequencies, indicating that the two time-series comove strongly around these scales. In addition, Fig (8c) gives more information about the phase (anti-phase) and the lead (lag) relationships of the two respective time series. This plot reveals that UK Uncertainty index and the corresponding interest rate are, in general, in anti-phase $[\pi / 2,-\pi / 2]$ from the beginning of the period to the end of 2012, with the interest rate leading the uncertainty index. From 2013 to the end of the sample period, the two time-series move in phase $[0, \pi / 2]$, where again the interest rate leads the uncertainty index. 


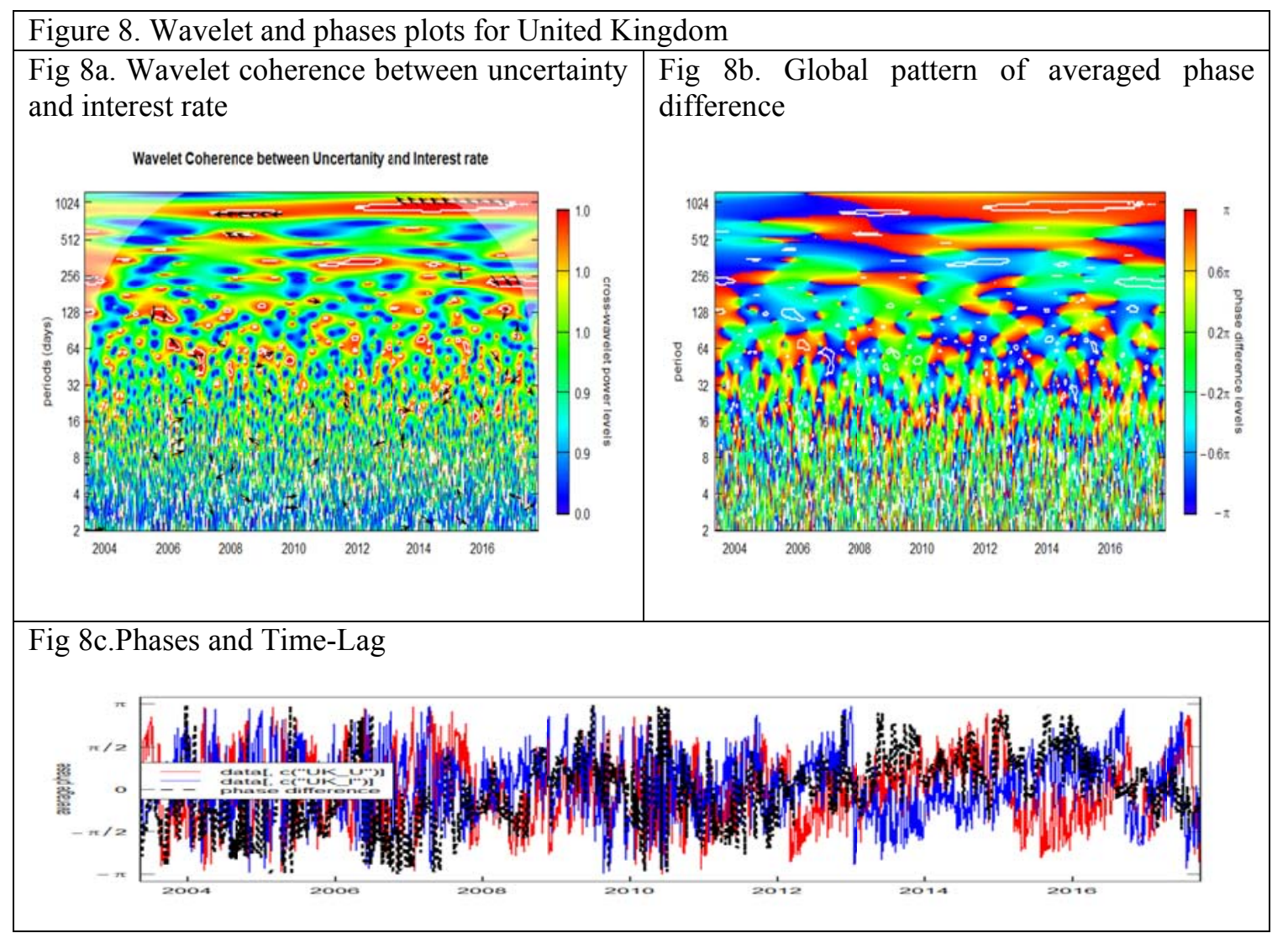

Note: a) Wavelet coherency between uncertainty index and interest rate, b) Global pattern of averaged phase difference, c) The phases and Time-Lag. The white contour identifies the regions in which the spectrum is significant at the $5 \%$ level against red noise. The cone of influence (COI), indicated by the lighter shade which delimits the high power regions. Time and frequency (daily) are represented on the horizontal and vertical axes, respectively.

\subsection{Wavelet coherency, phase difference analysis for Canada}

A visual inspection of figures Fig.9a; Fig.9b and Fig.9c, corresponding respectively to the wavelet coherence, the global phase difference and the phase differences plots, reveals a strong comovement between the Canadian uncertainty index and the interest rate. The highest level of comovement is concentrated within the 32-256 frequency band (medium scales) over the sample period where the arrows generally point right and down (in anti-phase), indicating that the uncertainty index leads the interest rate in Canada. We also find strong localized comovement at high scales during the period 2011-2013, where the arrows point to the left, indicating that the two series are in phase. The phase differences plot shown in Fig 9c indicates that the two timeseries broadly exhibit anti-phase characteristics. In addition, the plots specifically show that the patterns of the two phases vary over the sample period. First, an anti-phase relation between uncertainty index and interest rate is exhibited for the period 2004-end of 2011, where the phase 
difference is $\in[\pi / 2,-\pi / 2]$,demonstrating that the uncertainty index leads the interest rate. For the period 2011-2013 where the interest rate leads the uncertainty index in anti-phase relationship, the phase difference is $\in[\pi / 2, \pi]$.

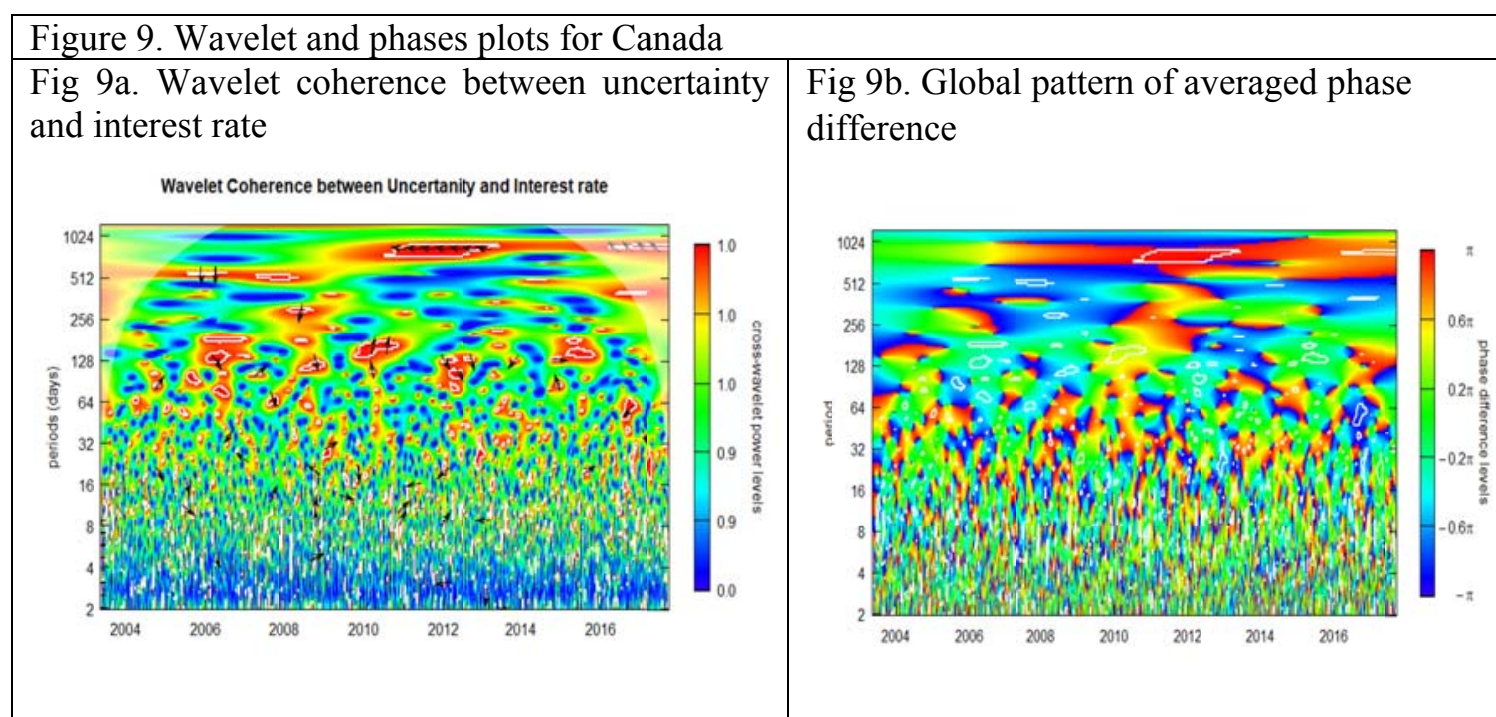

Fig 9c. Phases and Time-Lag

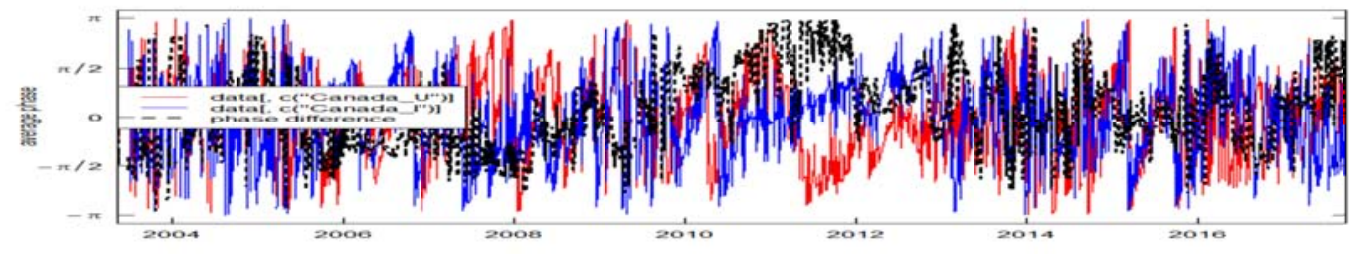

Note: a) Wavelet coherency between uncertainty index and interest rate, b) Global pattern of averaged phase difference, c) The phases and Time-Lag. The white contour identifies the regions in which the spectrum is significant at the $5 \%$ level against red noise. The cone of influence (COI), indicated by the lighter shade which delimits the high power regions. Time and frequency (daily) are represented on the horizontal and vertical axes, respectively.

\subsection{Wavelet coherency, phase difference analysis for Japan}

Figures $10 \mathrm{a}, 10 \mathrm{~b}$ and $10 \mathrm{c}$ represent the wavelet coherence, the global phases difference pattern and the average phase differences, respectively. Fig (10a)reveals small areas of red colors dispersed over the sample period and mostly concentrated within the 64-256 frequency band. The arrows are generally pointed to the right and down between 2004 and 2011 and are directed to the left and up during 2015-2016 for the same frequency band. These results indicate the existence of remarkable events at the beginning and the end of the sample period and also a change in the lead-lag relation between the uncertainty index and the interest rate for Japan. The average phase 
difference shows that, in general, the two time-series are in phase $[\pi / 2,-\pi / 2]$ and the interest rate leads the uncertainty index. The change in lead-lag relation is also apparent in the average phase difference for the period (2015-2016) and the two time-series are in phase $[0, \pi / 2]$ and the uncertainty index leads the interest rate.

\begin{tabular}{|l|l|}
\hline \multicolumn{3}{|l|}{ Figure 10. Wavelet and phases plots for Japan } \\
\hline $\begin{array}{l}\text { Fig 10a. Wavelet coherence between } \\
\text { uncertainty and interest rate }\end{array}$ & $\begin{array}{l}\text { Fig 5b. Global pattern of averaged phase } \\
\text { difference }\end{array}$ \\
\hline
\end{tabular}
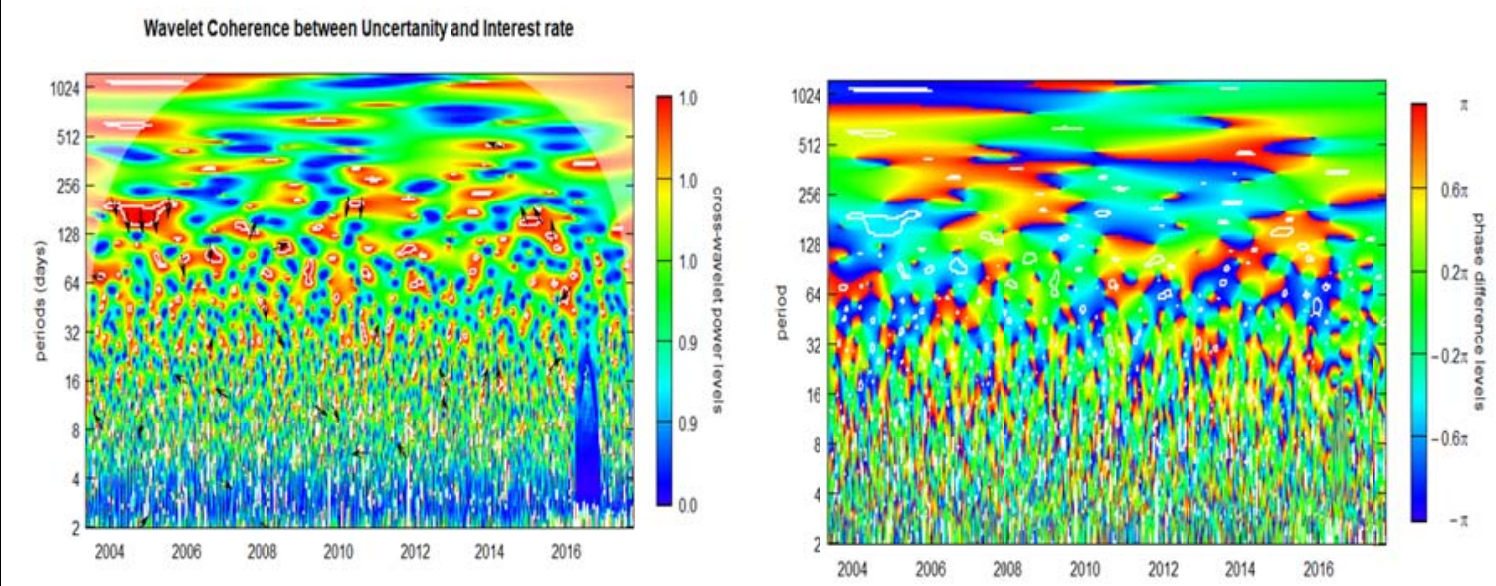

Fig 10c.Phases and Time-Lag

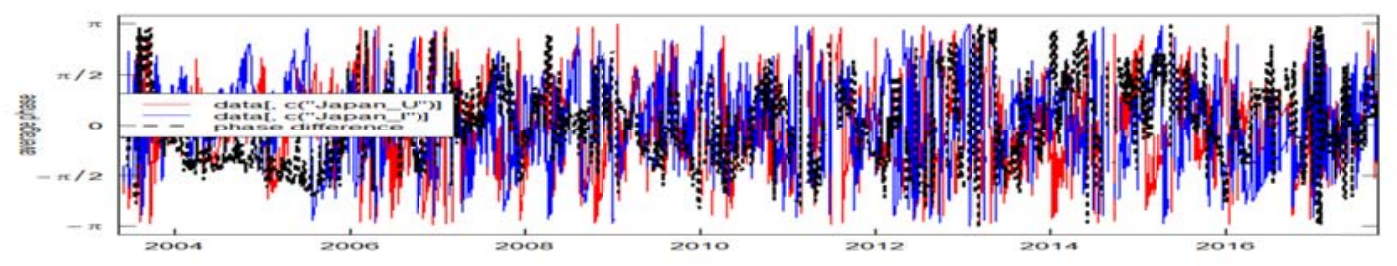

Note: a) Wavelet coherency between uncertainty index and interest rate, b) Global pattern of averaged phase difference, c) The phases and Time-Lag. The white contour identifies the regions in which the spectrum is significant at the $5 \%$ level against red noise. The cone of influence (COI), indicated by the lighter shade which delimits the high power regions. Time and frequency (daily) are represented on the horizontal and vertical axes, respectively.

From the previous findings, we can conclude that, around the financial crisis, the US uncertainty jumped up and remained high impacting the economic policy and macroeconomic variables. In addition, our results indicate that for Europe and Canada uncertainty exhibits similar tendencies in comparison to the US, suggesting that uncertainty hikes in general, during periods of deep recessions are global in nature, given interlinkages of countries. 


\section{Economic and Financial implications}

The results carry important implications for the literature that is concerned with causality of uncertainty and the real economy. In the following, we will detail some of the implications of our results for the countries that we considered for the period of analysis.

\section{- $\underline{\mathrm{US}}$}

Figure 1 (Fig. 1a and Fig. 1b) depict the uncertainty index and the shadow interest rates for the US. As one can see in Figure 1a, uncertainty in the US spiked around the years 2004, 2006, 2008, 2013 and 2016. In Figure 1b, one can see the (shadow) interest rate. In 2004, the Federal Reserve decided to raise interest rates after conducting expansionary monetary policies for several years. This period, which also corresponds to the aftermath of the 2003 Gulf War appears to have raised uncertainty regarding the real economy. Similarly, in the midst of contractionary monetary policies in the following period, uncertainty reached high levels around November 2005. Not surprisingly, uncertainty reached a climax in the US around the collapse of Lehman Brothers in 2008 when the possibility of a financial meltdown became apparent. Before the financial crisis erupted in 2008, the Federal Reserve lowered interest rates after July 2007 when signs of the subprime mortgage crisis became apparent and continued with unconventional monetary policies until 2013. In the following period after 2013, uncertainty increased once more when the socalled "taper tantrum" started and the Federal Reserve announced it would end pursuing unconventional monetary policies. Uncertainty increased again after 2016 following concerns of trade and currency wars.

Against this background, we find that uncertainty and interest rates mostly exhibit an anti-phase relationship, where the interest rate leads for the periods 2004-2006 and 2012-2016, and uncertainty leads for 2007-2011. This result supports the finding of Gupta et al. (2018) that uncertainty shocks in the US lead to expansionary monetary policies.The finding also may indicate that during the financial crisis of 2008, when uncertainty was very high, interest rate decisions were a response to the increasing uncertainty that prevailed in the economy once the economy entered a recession. This confirms the finding of Bloom (2014) that uncertainty may have accounted for one-third of the drop in GDP after the 2008 financial crisis. During the remaining periods however, it is the interest rate that leads the uncertainty index, implying that causality ran in the other direction for these periods. ${ }^{9}$

\footnotetext{
${ }^{9}$ As a robustness check, we conducted the analysis for the US over the period of 25 th November 1985 to 29th May 2018 using different measures for uncertainty and monetary policy. For uncertainty, we used the
} 


\section{- $\quad$ Euro Area}

Figure 2 (Fig. 2a and Fig. 2b) depict the uncertainty index and the interest rate for the Euro Area. As is apparent, uncertainty was especially high during the periods around 2007, 2009, 2010 and 2012. The year 2007 was marked by signs of instabilities in financial markets in several countries in and around the Euro Area: banks in Spain, Germany and the UK showed signs of instability and the subprime mortgage crisis in the US was starting to make headlines. Surprisingly, 2008 is marked by relatively low uncertainty, whereas in 2009 the index increased. As Scotti (2016) explains, this may indicate that economic actors in the Euro Area were more uncertain about the economy when it entered and exited the recession than during the crisis. Uncertainty once more increased in 2010 when Greece was bailed out after 2011 when the sovereign debt crisis affected several Euro Area economies.

During this period, interest rates also went through several stages. Interest rates fluctuated around the 2 percent band until 2005, after which they were raised until July 2008 when the financial crisis became apparent in the US. While coming close to the zero lower bound around May 2010 (during the Greece bail-out), interest rates slightly increased again until July 2011. The period after 2012 is marked by the effects of unconventional policies, especially after ECB president Mario Draghi announced in July 2012 that the ECB would do whatever it takes to preserve the currency.

These events and movements suggest that the results of the wavelet analysis for the Euro Area may stay in contrast to the results for the US. Specifically, our results show that interest rates and uncertainty comove in a phase relationship, where the interest rate leadsuncertainty for the period 2007-2011, anduncertainty leads the interest rate for the periods 2004-2008 and 2011-2016. The contrasting resultsare not surprising as the interest rate and the uncertaintyindex for the Euro Area

news-based daily data developed by Baker et al. (2016), which is a daily news-based Economic Policy Uncertainty Index based on newspaper archives from Access World News Bank service and is downloadable from: http://policyuncertainty.com/us_monthly.html. The primary measure for this index is the number of articles that contain at least one term from each of three sets of terms: "economic or economy"; "uncertain or uncertainty", and; "legislation or deficit or regulation or congress or federal reserve or white house". For monetary policy, we used the SSR and the expected monetary stimulus (EMS), which are both sourced from Krippner (2012, 2013) at: https://www.rbnz.govt.nz/research-and-publications/researchprogramme/additional-research/measures-of-the-stance-of-united-states-monetary-policy. Understandably, the SSR and EMS are negatively correlated. Based on the phase-difference results reported in figures A6 and A7, we find that the relationship between interest rates and uncertainty is mostly anti-phase, while that between EMS and uncertainty is in-phase, thus confirming the theory in general. In essence, over the common period of analysis, the uncertainty index of Scotti (2016) is qualitatively similar to the one obtained with the news-based index of Baker et al. (2016). 
exhibit different characteristics in comparison to US variables;interest rates were lowered following signs of the financial crisis of 2008 in the Euro Area, but the dramatic lowering of interest rates only following the sovereign debt crisis that encompassed several Euro Area economies after 2011. Similarly, while uncertainty reached a climax in the US around the time of the Lehman Brothers collapse and was relatively lower in the following period, uncertainty in the Euro Area reached high levels before and after the financial crisis, and around the time when the sovereign debt crisis erupted in Greece.

- $\underline{\mathrm{UK}}$

Figure 3 (Fig. 3a and Fig. 3b) display interest rates and the uncertainty index for the UK. It is clear from the figure that uncertainty in UK was relatively low until the end of 2008. After this period, which corresponds to the immediate aftermath of the eruption of the financial crisis in the US, uncertainty reached a climax and remained relatively high. Events that might have contributed to subsequent rounds of uncertainty include the sovereign debt crisis surrounding the Euro Area, the Brexit vote of June 2016 and the triggering of Article 50 in March 2017 that would initiate the exit of United Kingdom from the European Union. The conduct of monetary policy in the period of our analysis can be broken down into several subperiods. Interests were kept at relatively high levels until July 2008, i.e. the period preceding the financial crisis. During the first few months of the financial crisis, expansionary monetary policy measures pushed rates down to the zero lower bound. Following these measures, the Bank of England implemented successive rounds of quantitative easing in November 2009, October 2011, July 2012. While the shadow interest rate became positive in 2014, Bank of England announced another round of quantitative easing in August 2016 following the Brexit vote in June 2016, thereby pushing shadow rates into the negative territory once more. Finally, in November 2017 Bank of England raised interest rates.

Our results indicate that the shadow interest rate and uncertainty comoved in an antiphaserelationship from 2003 to the end of 2012, and in a phase relationship in the period 20132018. We also find that in the entire period interest rates lead the uncertainty index, implying a relationship where interest rate decisions lead to movements in the uncertainty index. ${ }^{10}$

\footnotetext{
${ }^{10}$ As for the US, using the news-based daily data on uncertainty developed by Baker et al., (2016) athttp://policyuncertainty.com/uk monthly.html, were-conducted the analysis over the period of $1^{\text {st January, }}$ 2001 to 29th May, 2018, and as measures of monetary policy, we use the SSR. Based on the phasedifference result reported in Figures A8, we find that the relationship between uncertainty and interest rates
} 


\section{- $\quad \underline{\text { Canada }}$}

Figure4 (Fig. 4a and Fig. 4b)depict the uncertainty index and the repo rate of Canada. The uncertainty index in Canada saw several short-lived increases in 2007. Similar to other countries that we analyze, there is elevated uncertainty for several years following the eruption of the financial crisis in 2008. While uncertainty remained high in the following years, it spiked again and reached a climax after 2016, when uncertainties surrounding trade wars and renegotiation of the NAFTA deal affected the Canadian economy.

In our analysis Canada stands out with regard to the conduct of monetary policy since it did not implement quantitative easing policies. Interest rates, which hovered between 2-4 percent until 2008,were decreased to 0.25 percent by April2009 and kept at that level until the second quarter of 2010. Between September 2009 and January 2015, interest rates were kept at 1 percent decreased again until June 2017. After that, Bank of Canada successively raised interest rates. As described in the previous section, the relationship between uncertainty and interest rates comoved in an anti-phase relationship for the period of our analysis. Within this period, uncertainty lead interest rates for the period 2004-2011 and interest rates lead uncertainty for the period 2011-2013. In the last several years of the analysis, the lead-lag relationship became less clear; uncertainty lead in the first few months of 2016 and for the period 2017-2018, whereas interest rates lead for the remaining part of 2016.

\section{- $\underline{\text { Japan }}$}

Figure 5 (Fig. 5a and Fig. 5b) show uncertainty and the shadow interest rate for Japan. Japan's economy exhibited relatively low levels of uncertainty until the financial crisis of 2008. This event and other events such as the resignation of Prime Minister Fukuda in September 2008 and general elections in August 2009 caused uncertainty to be elevated for several years. Amid these developments, the index spiked in March 2011 and reached its highest level in our observation period when Japan was struck by a tsunami and a nuclear plant was affected as a result. In most of the following period, the index remained at levels that were prevalent after the financial crisis. Japan was also one of the countries that implemented unconventional monetary policy measures after the financial crisis. While Japan followed other countries in this, unconventional policies

are mostly anti-phase. Again, as in the case of the US, over the common period of analysis compared to the uncertainty index of Scotti (2016) is qualitatively similar to those obtained with the news-based index of Baker et al., (2016). 
had been implemented several years prior to the financial crisis of 2008. In 1999, Bank of Japan had introduced a zero-interest rate policy to combat deflation andimplemented quantitative easing measures between 2001-2006. This period was followed by moderate increases in the interest rate and reached 0.5 percent. Following the financial crisis, Japan followed other central banks and decreased interest rates once more. After the Bank of Japan started implementing additional rounds of quantitative easing, shadow interest rates went into the negative territory and remained there for the remaining period of our analysis (see Kuroda (2016) for a brief account of unconventional policies implemented by Bank of Japan).

As explained above, our findings suggest that the shadow interest rate and the uncertainty index mostly move in a phase relationship and that for most of the analysis interest rates lead uncertainty. This may be indicative of Japan's position as the first country to have implemented quantitative easing measures and that monetary policy decisions are perceived to have significant consequences for the real economy.

\section{Conclusion}

The relationship between uncertainty and interest rates is a subject of growing interest for the macroeconomics literature. The debate regarding the nature of the relationship and causality has still not been settled conclusively.In this work we contributed to this literature by analyzing this relationship for several advanced economies in an empirical setup using daily data and wavelets. Although in our analysis we consider only advanced economies, these faced different challenges for the observation period under consideration and applied different versions of unconventional policies ${ }^{11}$. Correspondingly we find that in some of the countries uncertainty and interest rates mostly comove positively (EU and Japan) while in others they comove negatively (Canada, UK, US). We also find that causality between uncertainty and interest rates is not linear and can also change over time. These results carry importance for the ongoing debate since they imply that causality and the nature of the relationship are subject to changes over time and frequencies. Our findings also suggest that the relationship does not remain equal across countries and drawing generalized conclusions with regard to the relationship may not be correct. Since daily data on interest rates and uncertainty are so far only available for few advanced countries, our analysis is

\footnotetext{
${ }^{11}$ See Dell'Ariccia et al. (2018) for a description of unconventional policies pursued by the Euro Area, Japan and the United Kingdom.
} 
limited to those economies. Future work could shed light on this subject for emerging and developing markets when data becomes available.

\section{References}

Aguiar-Conraria, L., Azevedo, N., \& Soares, M. J. (2008). Using wavelets to decompose the time-frequency effects of monetary policy. Physica A: Statistical mechanics and its Applications, 387(12), 2863-2878.

Alexopoulos, M., \& Cohen, J. (2015). The power of print: Uncertainty shocks, markets, and the economy. International Review of Economics \& Finance, 40, 8-28.

Baker, S., Bloom, N., and Davis, S. (2016). Measuring economic policy uncertainty. Quarterly Journal of Economics, 131, 1593-1636.

Baldwin, R., \& Krugman, P. (1989). Persistent trade effects of large exchange rate shocks. The Quarterly Journal of Economics, 104(4), 635-654.

Baruník, J., Vácha, L.\& Krištoufek, L. (2011). 'Comovement of Central European stock markets using wavelet coherence: Evidence from high-frequency data. IES Working paper 22/2011, IESFSV. Charles University.

Baruník, J., and Kley, T. (2015). Quantile Coherency: A General Measure for Dependence between Cyclical Economic Variables. The Econometrics Journal.

Ben Salha, O., Hkiri, B., Aloui, C. (2018). Sectoral energy consumption by source and output in the US: New evidence from wavelet based-approach. Energy Economics 72, 75-96.

Bloom, N. (2009). The impact of uncertainty shocks. Econometrica, 77(3), 623-685.

Bloom, N. (2014). Fluctuations in uncertainty. Journal of Economic Perspectives, 28(2), 153-76.

Bordo, M.D., Duca, J.V \& Koch, C. (2016). Economic Policy Uncertainty and the Credit Channel: Aggregate and Bank Level U.S. Evidence Over Several Decades. FRB of Dallas Working Paper No.1605.

Brainard, W. C. (1967). Uncertainty and the Effectiveness of Policy. The American Economic Review, 57(2), 411-425.

Christou, C., Naraidoo, R., \& Gupta, R. (2018). Conventional and Unconventional Monetary Policy Reaction to Uncertainty in Advanced Economies: Evidence from Quantile Regressions. Studies in Nonlinear Dynamics and Econometrics. Forthcoming.

Connolly, R., Dubofsky, D., \& Stivers, C. (2018). Macroeconomic uncertainty and the distant forward-rate slope. Journal of Empirical Finance, 48, 140-161.

Dell'Ariccia, G., Rabanal, P., \& Sandri, D. (2018). Unconventional Monetary Policies in the Euro Area, Japan, and the United Kingdom. The Journal of Economic Perspectives, 32(4), $147-172$.

Dixit, A. (1989). Entry and exit decisions under uncertainty. Journal of political Economy, 97(3), 620-638. 
Dixit, A. K \& Pindyck, R. (1994). Investment under uncertainty. Princeton University Press.

Donadelli, M. (2015). Google search-based metrics, policy-related uncertainty and macroeconomic conditions. Applied Economics Letters, 22(10), 801-807.

Fontaine, J. S., Suchanek, L., \& Yang, J. (2017). Unconventional Monetary Policy: The Perspective of a Small Open Economy?. Bank of Canada Review, 2017(Spring), 19-30.

Giannoni, M. P. (2002). Does model uncertainty justify caution? Robust optimal monetary policy in a forward-looking model. Macroeconomic Dynamics, 6(1), 111-144.

Grinsted, A., Moore, J. C., \& Jevrejeva, S. (2004). Application of the cross wavelet transform and wavelet coherence to geophysical time series. Nonlinear processes in geophysics, 11(5/6), 561-566.

Gupta, R., Lau, C. K. M., \&Wohar, M. E. (2018). The impact of US uncertainty on the Euro area in good and bad times: evidence from a quantile structural vector autoregressive model. Empirica, 1-16.

Gürkaynak, R. S., Sack, B., \& Swanson, E. (2005). The sensitivity of long-term interest rates to economic news: Evidence and implications for macroeconomic models. American economic review, 95(1), 425-436.

Hartzmark, S. M. (2016). Economic uncertainty and interest rates. The Review of Asset Pricing Studies, 6(2), 179-220.

Ho, S. P., Pan, C. S., Yeh, C. H., \& Hsu, Y. (2010). Characteristics of and relations between housing cycles and economic fluctuations: A time-frequency analysis. Manuscript.

Hudgins, L., Friehe, C. A., \& Mayer, M. E. (1993). Wavelet transforms and atmopsheric turbulence. Physical Review Letters, 71(20), 3279.

Krippner, L. (2012). Modifying Gaussian term structure models when interest rates are near the zero lower bound. Reserve Bank of New Zealand, Discussion Paper Series, No. DP2012/02.

Krippner, L. (2013). Measuring the stance of monetary policy in zero lower bound environments. Economics Letters, 118(1), 135-138.

Kuroda, H. (2016). The practice and theory of unconventional monetary policy. In Contemporary Issues in Macroeconomics (pp. 7-14). Palgrave Macmillan, London.

Leippold, M., \& Matthys, F. (2015). Economic policy uncertainty and the yield curve. Working Paper.

Ludvigson, S. C., Ma, S., \& Ng, S. (2015). Uncertainty and business cycles: exogenous impulse or endogenous response? (No. w21803). National Bureau of Economic Research.

Ma, J., Olson, E., \&Wohar, M. E. (2018). Nonlinear Taylor rules: evidence from a large dataset. Studies in Nonlinear Dynamics \& Econometrics, 22(1).

Rua, A., \& Nunes, L. C. (2009). International comovement of stock market returns: A wavelet analysis. Journal of Empirical Finance, 16(4), 632-639. 
Scotti, C. (2016). Surprise and uncertainty indexes: Real-time aggregation of real-activity macrosurprises. Journal of Monetary Economics, 82, 1-19.

Söderström, U. (2002). Monetary policy with uncertain parameters. Scandinavian Journal of Economics, 104(1), 125-145.

Torrence, C., \& Compo, G. P. (1998). A practical guide to wavelet analysis. Bulletin of the American Meteorological society, 79(1), 61-78.

Torrence, C., \& Webster, P. J. (1999). Interdecadal changes in the ENSO-monsoon system. Journal of Climate, 12(8), 2679-2690.

Vacha, L., Janda, K., Kristoufek, L., \& Zilberman, D. (2013). Time-frequency dynamics of biofuel-fuel-food system. Energy Economics, 40, 233-241. 


\section{APPENDIX:}

Figure A1. Quantile Coherency between Uncertainty Index and Interest Rate in the US
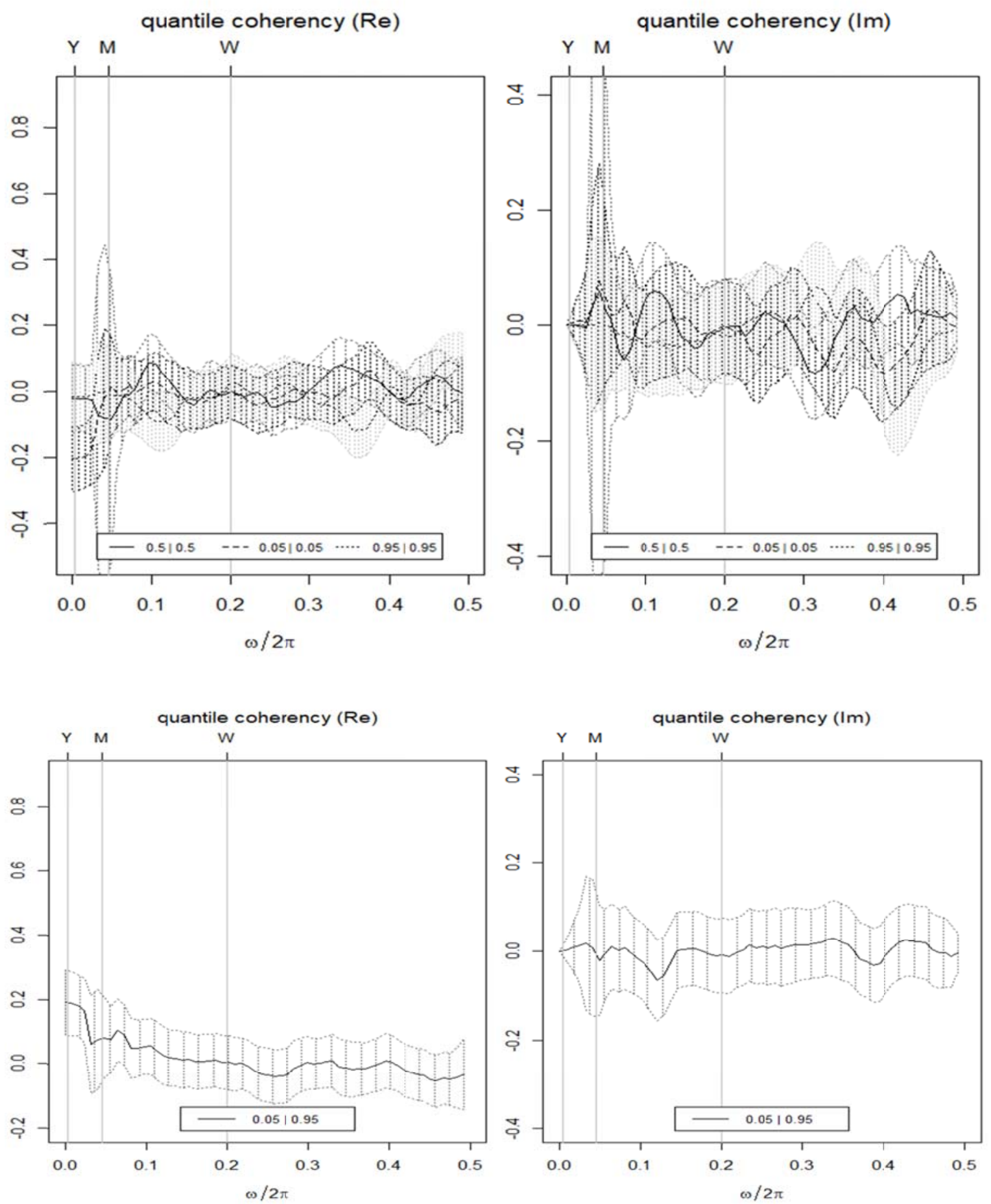
Figure A2. Quantile Coherency between Uncertainty Index and Interest Rate in Europe
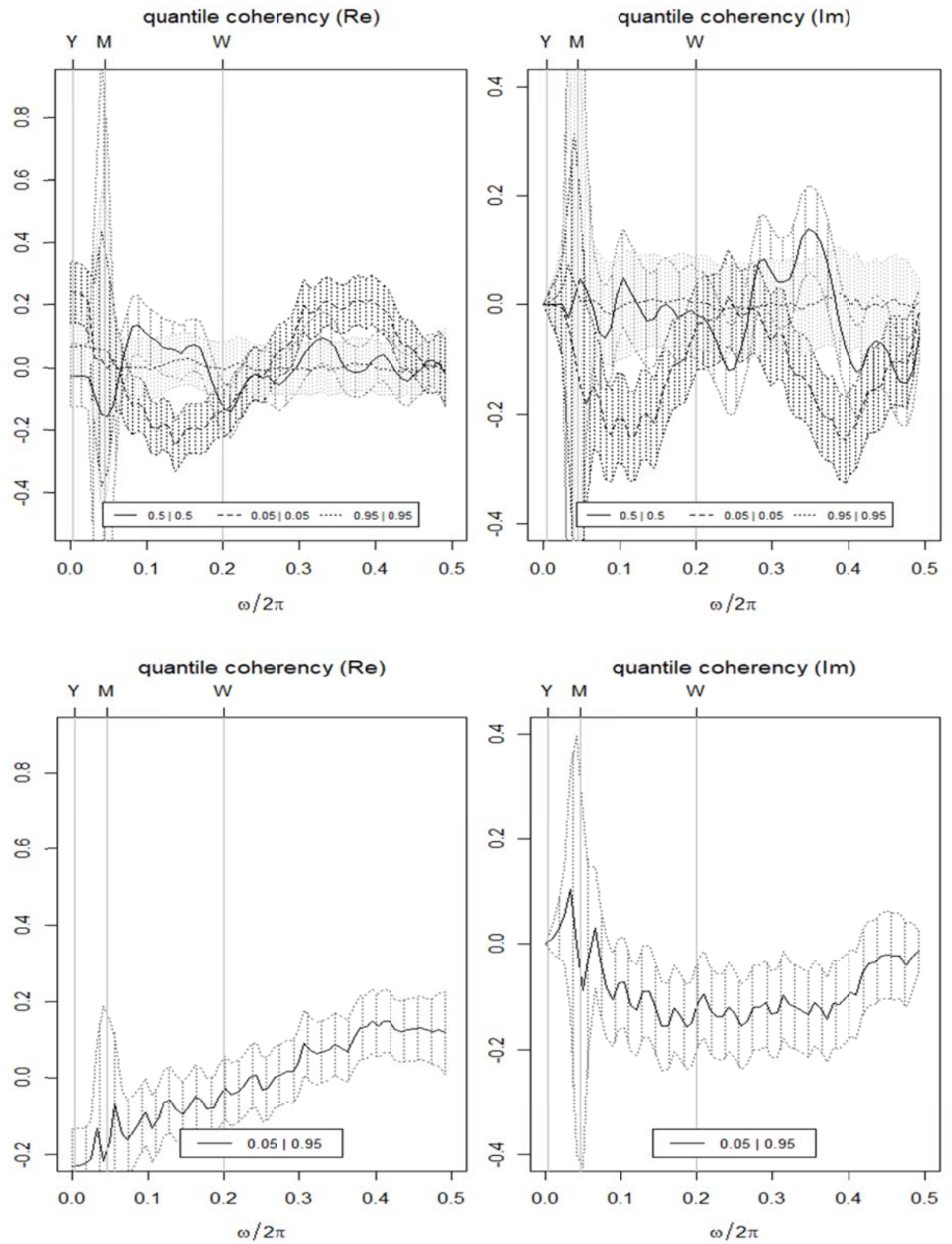
Figure A3. Quantile Coherency between Uncertainty Index and Interest Rate in the UK
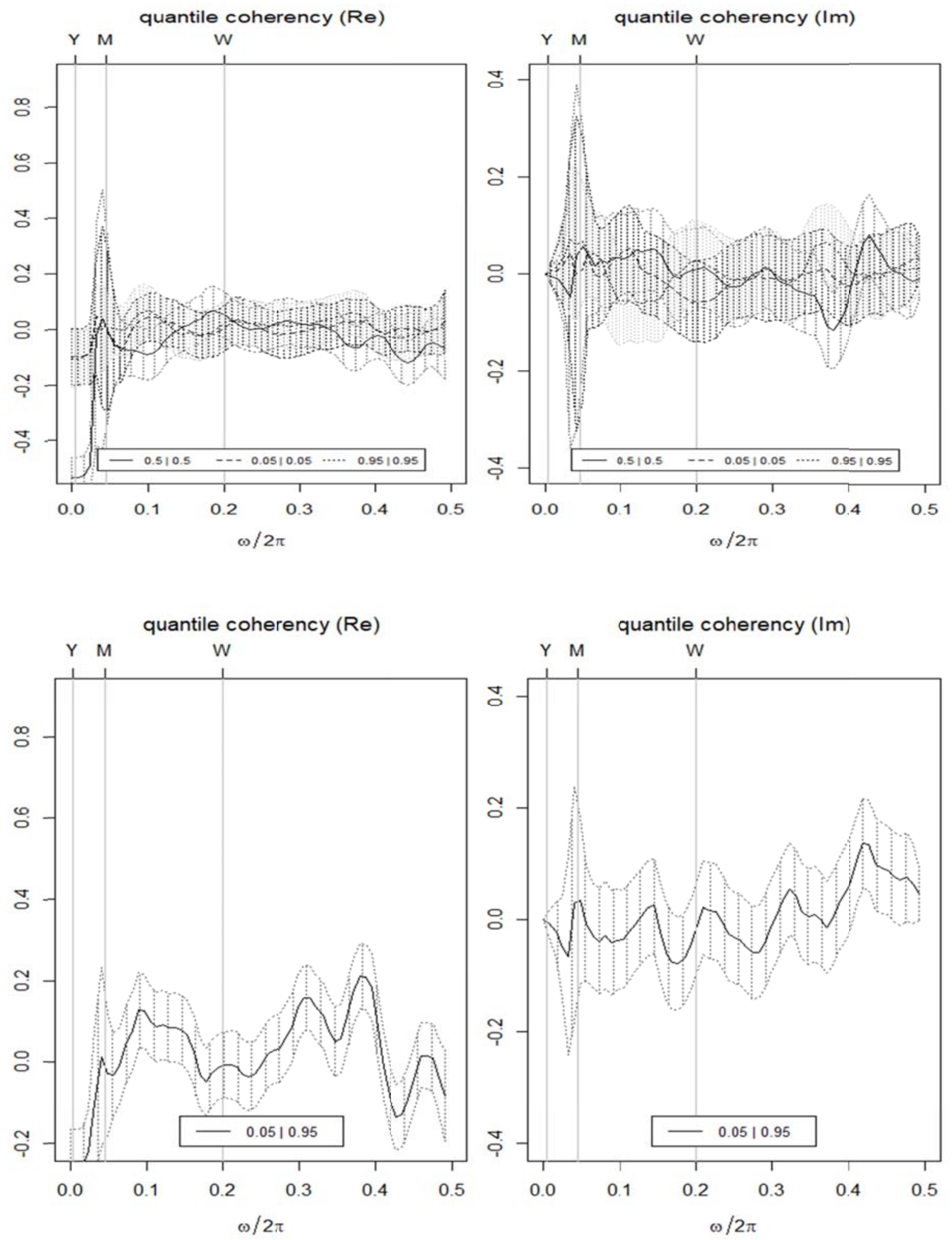
Figure A4. Quantile Coherency between Uncertainty Index and Interest Rate in Canada
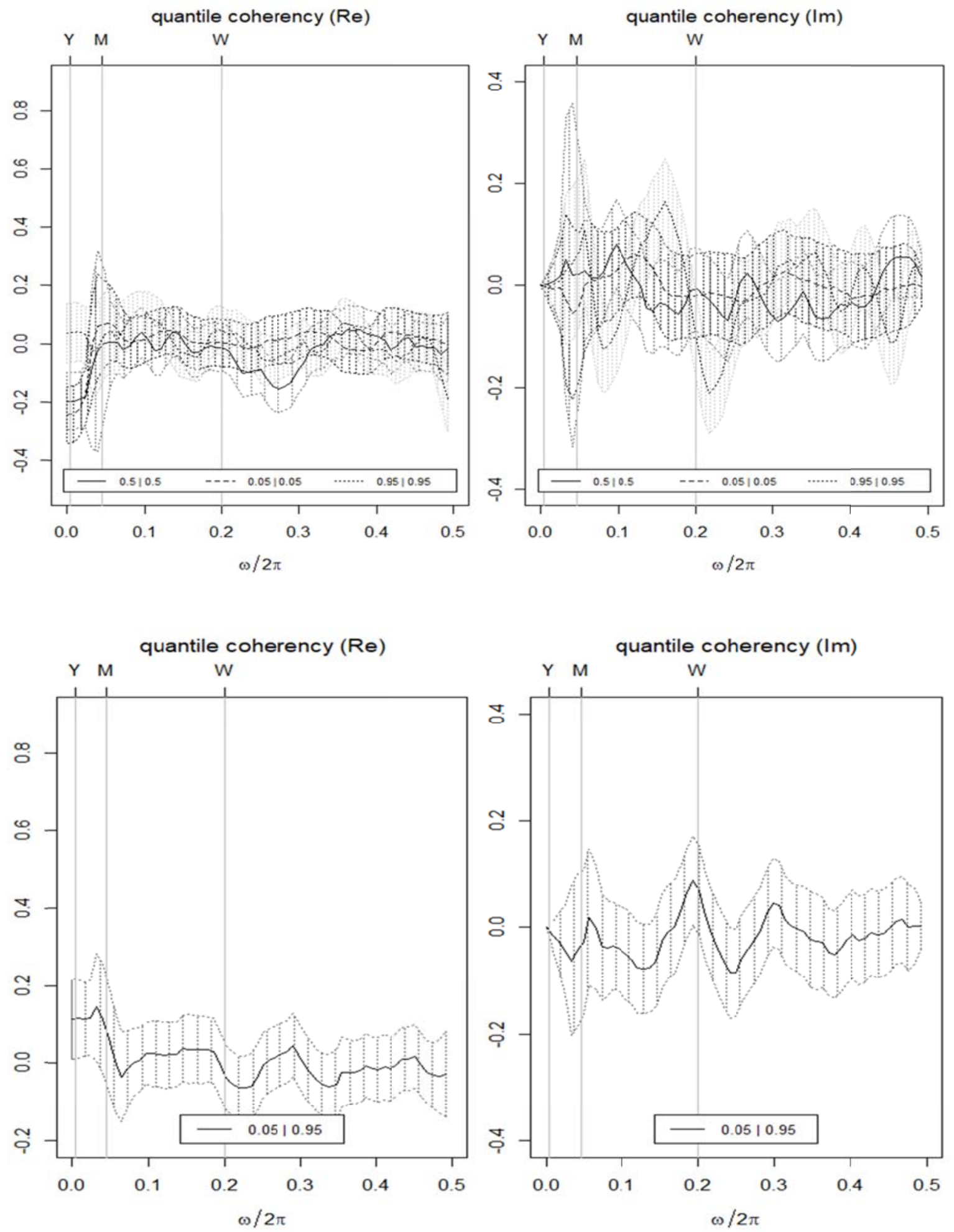
Figure A5. Quantile Coherency between Uncertainty Index and Interest Rate in Japan
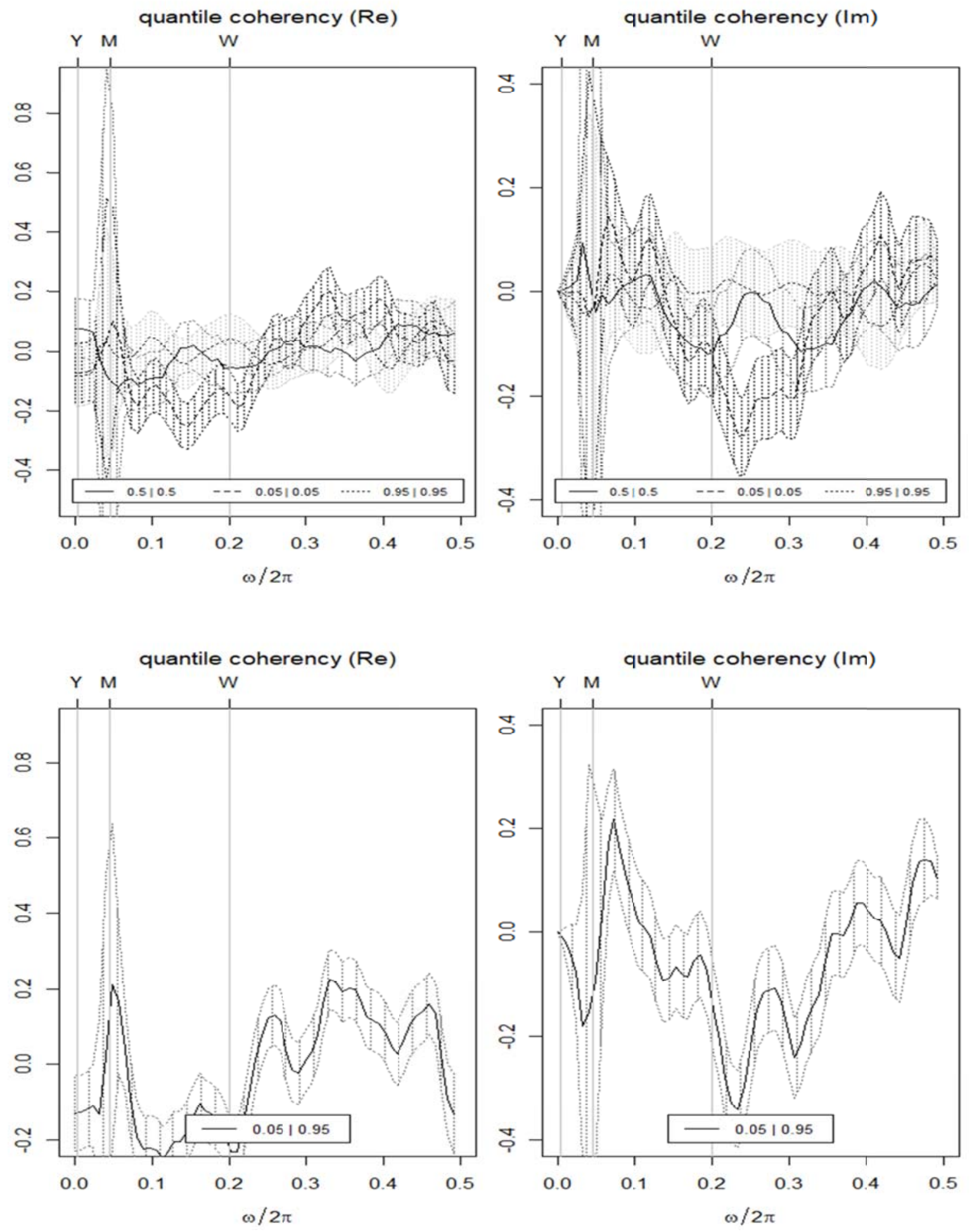
Figure A6. News-Based Uncertainty Index and Interest Rate of the US

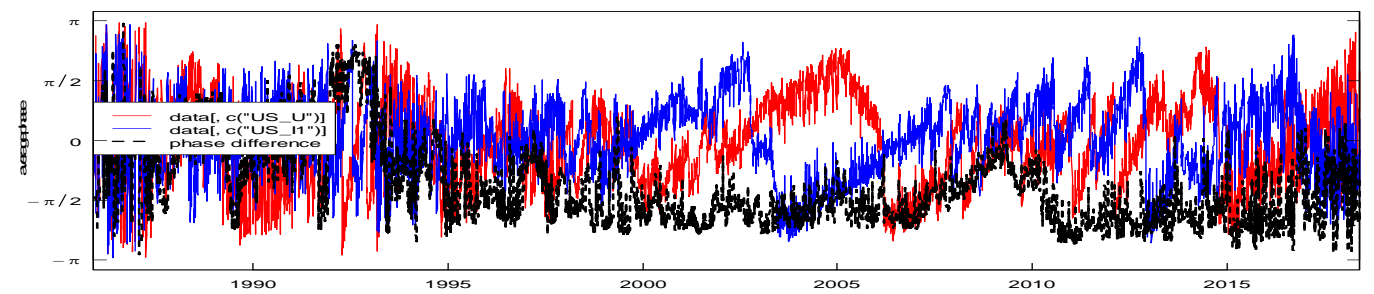

Figure A7. News-Based Uncertainty Index and Effective Monetary Stimulus of the US

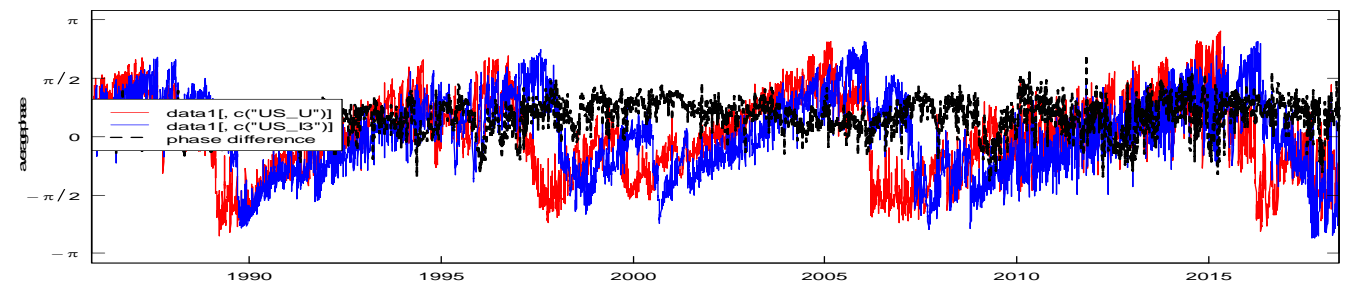

Figure A8. News-Based Uncertainty Index and Interest Rate of the UK

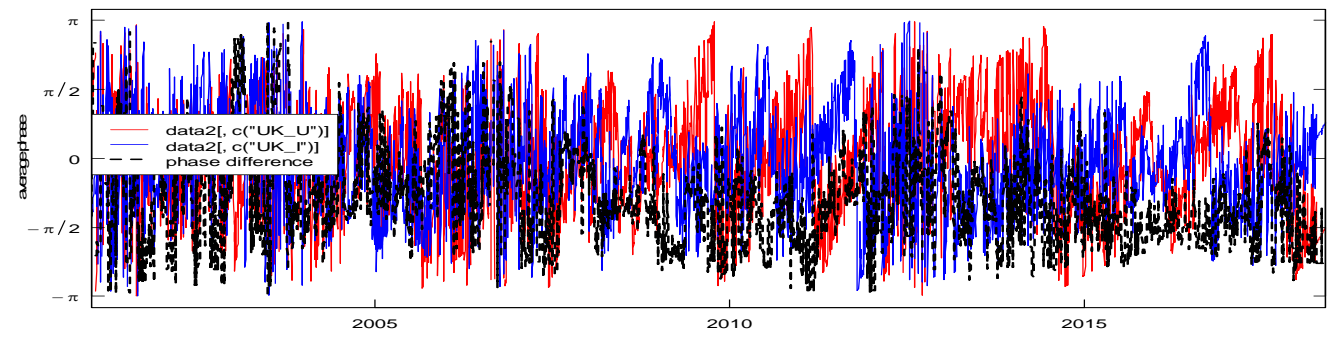

